\title{
SUSTAINABLE SLOPES: SATISFYING RAINFALL-EROSION EQUILIBRIUM AND MECHANICAL STABILITY
}

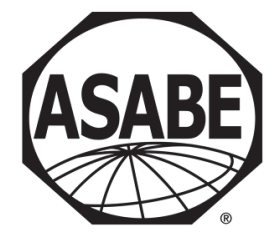

\author{
I. A. Jeldes, D. C. Yoder, E. C. Drumm
}

\begin{abstract}
While manmade slopes are traditionally constructed with planar cross-sections, natural stable slopes are usually curvilinear with significant concavity of the profile. This concavity occurs as a result of evolutionary processes in which rain-driven erosion and sediment transport are balanced through slope shape adjustments. At the point of equilibrium, a relatively steady concavity with a uniform erosion rate is observed over time. Nevertheless, a true equilibrium state is possible only if mechanical stability is satisfied. In this study, concave profiles in rainfall erosion equilibrium were found based on the principles of the well-known RUSLE2 model. Results showed the existence of a family of steady shapes satisfying the condition of uniform normalized erosion rate. Those steady concave shapes that also satisfied long-term mechanical stability were then investigated. The overall results suggest that concave slopes can be constructed to achieve both minimal steady-state erosion equilibrium and mechanical stability, leading to more natural and sustainable landforms with minimal sediment delivery during initial slope adjustments.
\end{abstract}

Keywords. Concave slopes, Erosion, Sustainable design, Slope stability.

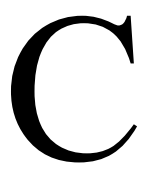

oncave profiles have been presented as a way to optimize both the mechanical stability of slopes (Gray, 2013; Jeldes, et al., 2015a, 2015b; Sokolovski1̌, 1960; Utili and Nova, 2007; Vahedifard et al., 2016a, 2016b; Zhang et al., 2017) and the water erosion resistance of slopes (Jeldes et al., 2015a; Rieke-Zapp and Nearing, 2005). Jeldes et al. (2015a) suggested an approach to combine the mechanical and erosional benefits of concave slopes that includes (1) a procedure to obtain concave contours with the desired degree of mechanical stability, and (2) quantification of the effectiveness of those slopes in reducing erosion and sediment delivery. This approach results in slopes that appear more natural and constitutes an eco-technical solution to the design of slopes as a function of familiar geotechnical engineering parameters. However, while those slopes are effective in reducing erosion and providing mechanical stability, their concave profiles may not be in equilibrium from an erosion perspective. Evidence exists that natural fluvial systems seek erosion and sediment transport equilibrium, and in doing so they adjust their geometry in order to achieve a steady-state form (Yang and Song, 1979) that will be relatively constant over time. This

(c) (i) $(\$)$ The authors have paid for open access for this article. This c. ${ }_{\mathrm{BY}} \mathrm{NC}_{\mathrm{ND}}$ work is licensed under a Creative Commons AttributionNonCommercial-NoDerivatives 4.0 International License https://creative commons.org/licenses/by-nc-nd/4.0/

Submitted for review in November 2017 as manuscript number NRES 12713; approved for publication by the Natural Resources \& Environmental Systems Community of ASABE in March 2018.

The authors are Isaac A. Jeldes, Project Engineer, Dan Brown and Associates, Knoxville, Tennessee; Daniel C. Yoder, Professor, and Eric C. Drumm, Professor, Department of Biosystems Engineering and Soil Science, University of Tennessee, Knoxville, Tennessee. Corresponding author: Isaac A. Jeldes, 6424 Baum Drive, Knoxville, TN 37919; phone: 865-999-3936; e-mail: ijeldes@dba.world. shape is usually referred to as an equilibrium shape, with a concave form characterized by parallel retreat (Penck, 1953; Schumm, 1956; Twidale, 2007). In other words, manmade slopes (e.g., planar slopes) undergo continuous changes in slope morphology triggered by water erosion forces to ultimately achieve this equilibrium condition. During this process, large amounts of soil are eroded. Geomorphological evolution toward an erosion equilibrium state does not imply that the resulting slopes are mechanically stable. A true equilibrium state will be achieved only when both erosion equilibrium and long-term mechanical gravitational stability are satisfied. If slopes can be designed and constructed with a shape that minimizes sediment delivery and provides substantial slope stability, the overall result should be a more natural and sustainable design. The question becomes whether we can describe such sustainable slopes when both erosion and mechanical equilibrium requirements are met.

In this article, the concept of steady-state landforms is explored, and changes in slope morphology toward a concave erosion equilibrium shape are described. Using the fundamental relationships of the RUSLE2 erosion model, concave profiles in water erosion equilibrium are identified and described, and a simple approach to determine those long-term mechanically stable erosion equilibrium shapes is proposed for any given combination of soil stresses and strength. A definition of the approximate limiting erosion rate at which equilibrium erosion shapes become mechanically stable and thus sustainable is explored, and a mathematical expression to obtain this limiting erosion rate is offered as a function of the Mohr-Coulomb soil strength parameters. 


\section{BACKGROUND}

\section{Concave Profiles as Erosion EQUILIBRIUM SHAPES}

In nature, slope profiles are rarely uniform but are usually curvilinear. This seems to be the result of a natural geomorphological evolution process of streams and slopes in which an optimum equilibrium profile is sought (Schor and Gray, 2007). According to Leopold and Langbein (1962), the distribution of the energy in a fluvial system tends toward a state of maximum entropy, which is characterized by a uniform energy dissipation in which the same energy dissipation is experienced at each point in the landscape (Miyamoto et al., 2005). Leopold and Langbein (1962) showed that the most probable longitudinal profile in a fluvial system is concave. Later studies have validated Leopold and Langbein's ideas (Molnár and Ramírez, 1998; Rodríguez-Iturbe et al., 1992; Yang and Song, 1979) and have introduced new concepts, such as minimum entropy production as a characteristic of the steady equilibrium of a geomorphic system (Miyamoto et al., 2005), and the concept of minimum rate of energy dissipation experienced by equilibrium shapes (Yang and Song, 1979). According to Yang and Song (1979), if fluvial systems deviate from an equilibrium state, the properties of slope inclination, roughness, channel geometry, and flow velocity will experience continuous adjustments in order to again achieve a steady equilibrium state. Other authors have also proposed concave profiles as the equilibrium or steady shape in fluvial systems (Goldrick and Bishop, 2007; Larue, 2008; Smith et al., 2000; Snyder et al., 2000).

Steady concave shapes have also been proposed as the result of hillslope evolution. According to Pelletier and Rasmussen (2009), slopes in more humid areas tend to be more complex in cross-section (concave slope with convexity in the upper portion), while slopes in more arid regions tend to have concave forms. According to Schumm (1956), complex slope shapes are formed mainly by gravity-driven forces because soils in humid areas are usually covered by thick vegetation and the role of water erosion is reduced. On the other hand, when the slope surface is affected by rainfall-driven erosion, the formation of concave equilibrium slopes is expected (Schumm, 1956), and, at the point of equilibrium, parallel or lateral slope retreat occurs as the equilibrium concave shape is maintained over time (Nash, 1980; Pelletier and Rasmussen, 2009; Schumm, 1956). The equilibrium shape is characterized by a uniform rate of erosion everywhere on the slope profile (Hack, 1960; Montgomery, 2001). Twidale and Milnes (1983) proposed that parallel retreat in concave slopes occurs sequentially in a series of soil movement stages starting from the slope toe and evolving upward until the same slope concavity shape is formed again.

This geomorphology concept of a steady-state condition is not exempt from criticism. Bracken and Wainwright (2008) reviewed several methods employed to measure geomorphological equilibrium and concluded that the lack of a precise definition of the spatial and temporal scales in geomorphology evolution makes many of the ideas related to steady forms untestable. Phillips (2011) stated that although steady-state conditions are sometimes observed in nature, they are not a realistic representation of how geomorpho- logic evolution works in general. He also suggested that the idea of concave profiles as the equilibrium shape in fluvial systems is not well supported by empirical or theoretical evidence, casting doubt on the Yang and Song (1979) concept of continuous system adjustments to reach equilibrium. Nevertheless, the fact that geomorphological studies cannot explain or include every variable involved in this complex behavior does not imply that these studies explain nothing. As Phillips (2011) recognized, steady-state assumptions have been useful in interpreting and modeling the evolutionary behavior of earth systems. Furthermore, there is a universal tendency for all natural processes, including geomorphological systems, to adjust and readjust themselves to dynamic equilibrium, i.e., through continuous adjustments between processes like erosion and soil resistance (Abrahams, 1968; Ahnert, 1994). Through these dynamic adjustments, steadystate landform shapes may be obtained (Abrahams, 1968; Thorn and Welford, 1994). Steady-state forms may indeed be dependent on the time scale and require unchanging boundary conditions (Thorn and Welford, 1994), but if any external agent disturbs this steady equilibrium condition, dynamic adjustments will occur, so the system will be naturally reshaped to re-obtain the steady-state form under the new conditions.

\section{SLOPE SHAPE EVOLUTION AND EQUILIBRIUM PROFILES CONCEPTUAL MODEL}

Because water erosion on a hillslope is a process involving detachment by runoff flow, raindrop impact, flow energy, and sediment transport, the generalized principle of minimum rate of energy dissipation (Yang and Song, 1979) may be used to explain the concept of steady-state equilibrium shapes and parallel retreat observed in slope evolution. Here, a simple conceptual model is offered in an attempt to explain the changes in morphology of slopes actively eroded by water. For a slope in an initial unbalanced state (e.g., a planar slope), continuous changes in the slope geometry and water flow velocities are expected in order for the system to adjust and reach equilibrium. In this process, the overall erosion rate would gradually decrease until a constant rate of erosion along the profile is achieved. The evolution toward a constant rate of erosion implies a reduction in the difference in energy entering and leaving the system with respect to a previous point in time, eventually reaching a minimum. According to Hack (1960), the steady-state equilibrium of the landscape requires the existence of opposing forces counteracting and balancing each other, such that energy dissipation can exist. As explained below, these opposing forces can conceptually be the slope length and slope steepness.

Assuming that raindrop impact is even everywhere on the slope, erosion increases with slope length through the increase in cumulative runoff. The effectiveness of that runoff in detaching sediment or in transporting eroded sediment depends on both the runoff rate and on its turbulent energy, which for a defined surface condition is determined primarily by the slope steepness. On a planar slope, the steepness 


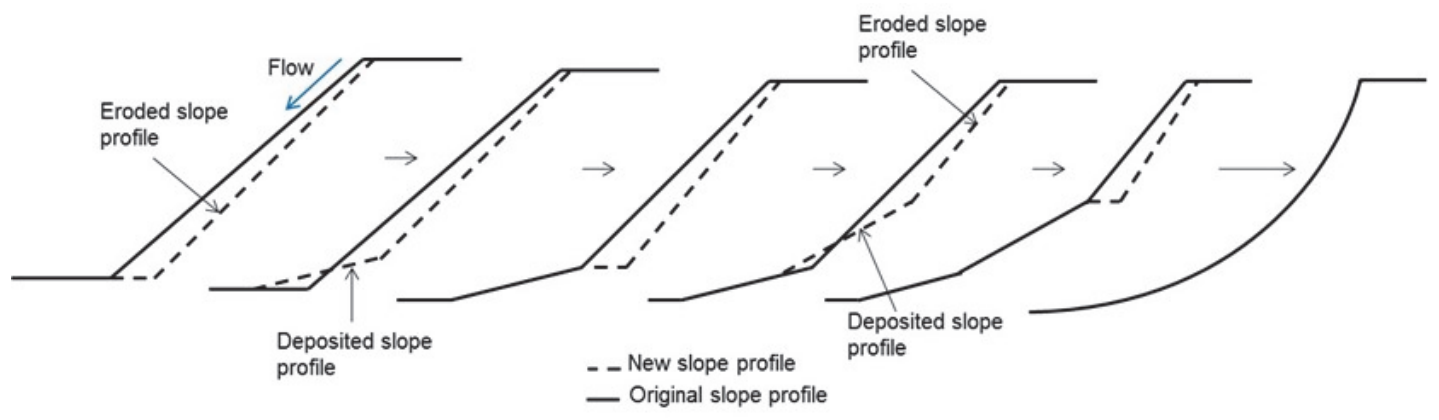

Figure 1. Conceptual model of slope morphology evolution by water erosion.

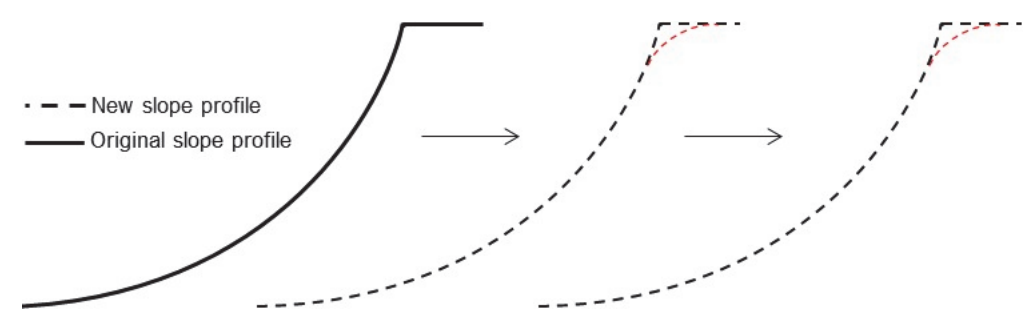

Figure 2. Illustration of the parallel retreat concept. The sharp edge at the top of the slope may be naturally eroded (becoming convex) if there is runoff coming over the top edge of the slope. This effect is not included in the proposed model.

is constant, so both the detachment and transport rates increase with distance downslope (fig. 1) due to the increasing slope length (Young and Mutchler, 1969). This results in a higher erosion rate at the lower portion of the slope, and consequently a faster retreat of that portion. In contrast, on a concave slope, the steepness decreases with increased slope length, so the increase in detachment and transport potential due to the increased slope length is counteracted by a reduction due to the decreased steepness. This is consistent with the idea of balanced opposing forces described by Hack (1960). This natural morphologic evolution toward a concave slope requires a combination of soil detachment along the hillslope and soil deposition at the slope base (fig. 1) until an equilibrium state is reached in which the concave geometry experiences a constant detachment and transport rate at every point along the slope. Once this shape is achieved, the slope profile will not suffer further adjustments, and the slope will erode in the parallel retreat mode illustrated in figure 2. If the slope deviates from this equilibrium shape, it will experience continuous adjustments until a new steady equilibrium state is reached.

Over time, in more humid areas, the sharp edge at the top of the slope seems to evolve to a convex form (fig. 2), yielding a more complex slope contour, as seen in many natural landscapes. It is not clear if this convexity is due to higherodibility soil conditions triggered by runoff coming over the top edge that infiltrates and saturates the soil, or due to a series of small mechanical failures caused by the steepness of the contour and the effects of transient flow through the top edge. Because the mechanisms behind the formation of convexity at the upper portion of the slope are not fully understood, this effect is not included in the development of the model in the subsequent sections.

\section{GENERAL APPROACH}

From the previous discussion, we conclude that physical processes shape slopes into concave profiles, and such pro- files represent a topographic equilibrium condition. Here, we concentrate not on modeling the time-scale geomorphological evolution of slopes but rather on describing the equilibrium shape that provides the necessary parallel retreat. Based on this approach, once the concave equilibrium shape has been developed, the mechanism controlling parallel retreat is erosion, so depositional processes do not need to be included in the description.

As described above, the steady-state concave shape is characterized by a uniform water erosion rate along the slope. However, many potential concave profiles can satisfy this condition, so the steady-state shape may not be unique. This may be explained using the widely recognized Revised Universal Soil Loss Equation (RUSLE2; USDA-ARS, 2008):

$$
A=R \cdot K \cdot L S \cdot C \cdot P
$$

where the predicted soil loss $A\left(\mathrm{Mg} \mathrm{ha}^{-1}\right.$ year $\left.^{-1}\right)$ is directly proportional to the rainfall erosivity $R(\mathrm{MJ} \cdot \mathrm{mm} / \mathrm{ha} \cdot \mathrm{h} \cdot$ year) quantifying the rainfall's erosive potential, the soil erodibility $K$ $(\mathrm{Mg} \cdot \mathrm{ha} \cdot \mathrm{h} / \mathrm{ha} \cdot \mathrm{MJ} \cdot \mathrm{mm})$ defining the soil's susceptibility to that erosivity, the topographic factor $L S$ (dimensionless) representing slope length and steepness effects, the surface cover factor $C$ (dimensionless), and the conservation practices factor $P$ (dimensionless). To observe solely the influence of the landscape topography or slope shape on the erosion rate, let us assume that all the variables remain constant across the landscape except the topographic factor $L S$, which corresponds to the combined action of the slope length factor $L$ and the slope steepness factor $S$. The length factor is not a function of the length along the profile but of the slope horizontal length $\lambda$. The steepness factor is a function of the angle of the slope with respect to the horizontal $\alpha$, and it varies in form depending on the relative values of steepness and horizontal slope length. The longer the horizontal slope length, the higher the observed erosion rate will be. Similarly, the steeper the slope, the higher 
the erosion rate will be. Because the steepness is constant in a planar slope, the erosion rate will uniformly increase downslope due to the increasing slope length. Figure 3 illustrates the erosion rate experienced by four different points on a planar slope profile having bare soil surface conditions, assuming that all other inputs are equal to one in order to display the relative position differences. At the top of the slope (point 0 ), erosion is mainly controlled by raindrop detachment (sheet erosion), and the erosion rate will be proportional to the slope angle only. At this point, little erosion is observed. As the runoff moves downslope it starts accumulating sufficient energy to detach soil particles, and that energy is directly proportional to the runoff length and the slope angle. Thus, at point 1 on the profile, the experienced erosion rate $A_{p 1}$ will be equal to the product of the length factor $L_{p 1}$ (a function of the horizontal slope length $\lambda_{p 1}$ ) and the steepness factor $S$ (a function of the slope angle $\alpha$ ). Further down the slope, runoff gains more energy due to the greater cumulative flow rate, so the erosion rate at point 2 will be greater than at point $1\left(A_{p 2}>A_{p 1}\right)$. Similarly, the erosion rate at point 3 will be greater than at point 2 , and the result is a continuously increasing erosion rate downslope $\left(A_{p 3}>A_{p 2}>A_{p 1}>A_{p 0}\right)$.

What if the increase in slope length (moving downslope) is counteracted by a decrease in the slope angle such that the erosion rate remains equal along the profile? This would be the case if the value of $L_{i} S_{i}$ is constant for all segments. The resulting shape of this compensation process would be concave, with a constant rate of erosion along the profile. Notice that the entire erosion phenomenon starts at the uppermost point of the slope, where only sheet erosion exists, and that sheet erosion is a function only of the slope angle. Different initial slope angles will yield different initial rates of erosion, resulting in different subsequent downhill combinations of lengths and angles in order to achieve the same rate of erosion everywhere. Thus, many concave shapes can satisfy the condition of a constant erosion rate, each with a different level of constant erosion controlled by the assumed angle of the top segment. Figure $4 \mathrm{a}$ shows a steep profile with an initial angle of $\alpha_{0 h}$ at the top of the slope and a high initial erosion rate $A_{0 h}=S\left(\alpha_{0 h}\right)$. To maintain this erosion production along the profile $\left(A_{0 h}=A_{1 h}=A_{2 h}=A_{3 h}\right)$, the angle of the slope $\alpha_{i}$ must continuously decrease. Notice that the erosion at $\lambda_{i}$ needs to be a function of $L_{i}$ and $S_{i}$, which in turn are functions of $\lambda_{i}$ and $\alpha_{i}$, respectively $\left(f\left[L_{i}\left(\lambda_{i}\right) \cdot S_{i}\left(\alpha_{i}\right)\right]\right)$. Figure $4 \mathrm{~b}$ shows a profile initially inclined at $\alpha_{0 m}$ at the top. Because $\alpha_{0 m}<\alpha_{0 h}$, the initial erosion rate for this case will be $A_{0 m}<A_{0 h}$, and the

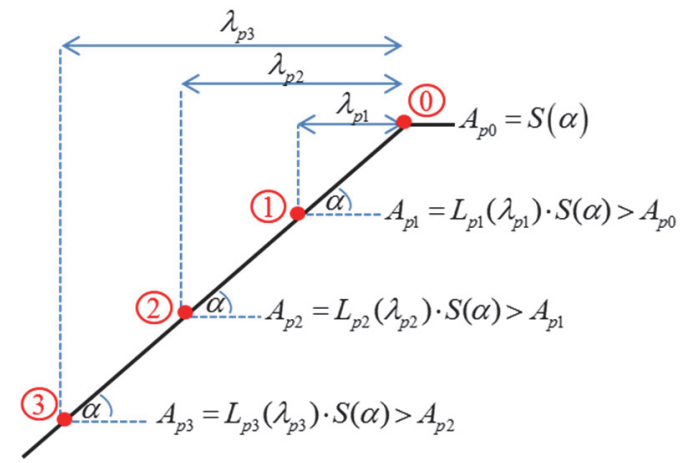

Figure 3. Erosion rates on a planar profile as modeled by RUSLE2. adjustment process to achieve a constant erosion rate will yield a profile somewhat less steep. Similarly, the case illustrated in figure $4 \mathrm{c}$ corresponds to an even gentler concave profile, due to an even smaller initial rate of erosion $A_{0 l}$. Notice that, for the same soil strength, an increase in mechanical stability from case (a) to case (c) is perceived due to the decrease in overall inclination.

\section{RUSLE2 APPROXIMATION TO STEADY-STATE CONCAVE SLOPES \\ Normalized Rate of Erosion and Equations for LS}

Following this approach, different levels of constant erosion will determine the concavity of the slope profile, starting from the initial angle at the top of the slope. To expand on this, let us first rewrite equation 1 and define a normalized erosion rate $A^{n}$ such that the amount of erosion is identical to the topographic factor $L S$ :

$$
A^{n}=\frac{A}{R \cdot K \cdot C \cdot P}=L S
$$

where $A^{n}$ is a dimensionless quantity of erosion, and $L S$ is a function of slope length and slope angle $[L S(\lambda, \alpha)]$. For hor-

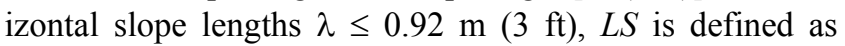
(USDA-ARS, 2008):

$$
L S=\left(\frac{4.6}{22.1}\right)^{m} \cdot\left(3 \cdot(\sin \alpha)^{0.8}+0.56\right)
$$

where $\alpha$ is the slope angle measured in degrees. The factor $m$ in equation 3 is called the slope length exponent and can be calculated as follows (Foster et al., 1977):

$$
m=\frac{\beta}{1+\beta}
$$

where $\beta$ is the ratio of rill to interrill erosion defined as (McCool et al., 1989):

$$
\beta=\frac{\sin \alpha / 0.0896}{3 \cdot(\sin \alpha)^{0.8}+0.56}
$$

For $\lambda \geq 4.6 \mathrm{~m}(15 \mathrm{ft}), L S$ is computed as:

$$
L S= \begin{cases}\left(\frac{\lambda}{22.1}\right)^{m} \cdot(10.8 \cdot \sin \alpha+0.3), & \alpha<5.1^{\circ} \\ \left(\frac{\lambda}{22.1}\right)^{m} \cdot(16.8 \cdot \sin \alpha-0.5), & \alpha \geq 5.1^{\circ}\end{cases}
$$

with $\lambda$ in $\mathrm{m}$ (SI units)

$$
L S= \begin{cases}\left(\frac{\lambda}{72.6}\right)^{m} \cdot(10.8 \cdot \sin \alpha+0.3), & \alpha<5.1^{\circ} \\ \left(\frac{\lambda}{72.6}\right)^{m} \cdot(16.8 \cdot \sin \alpha-0.5), & \alpha \geq 5.1^{\circ}\end{cases}
$$

with $\lambda$ in $\mathrm{ft}$ (U.S. customary units). 

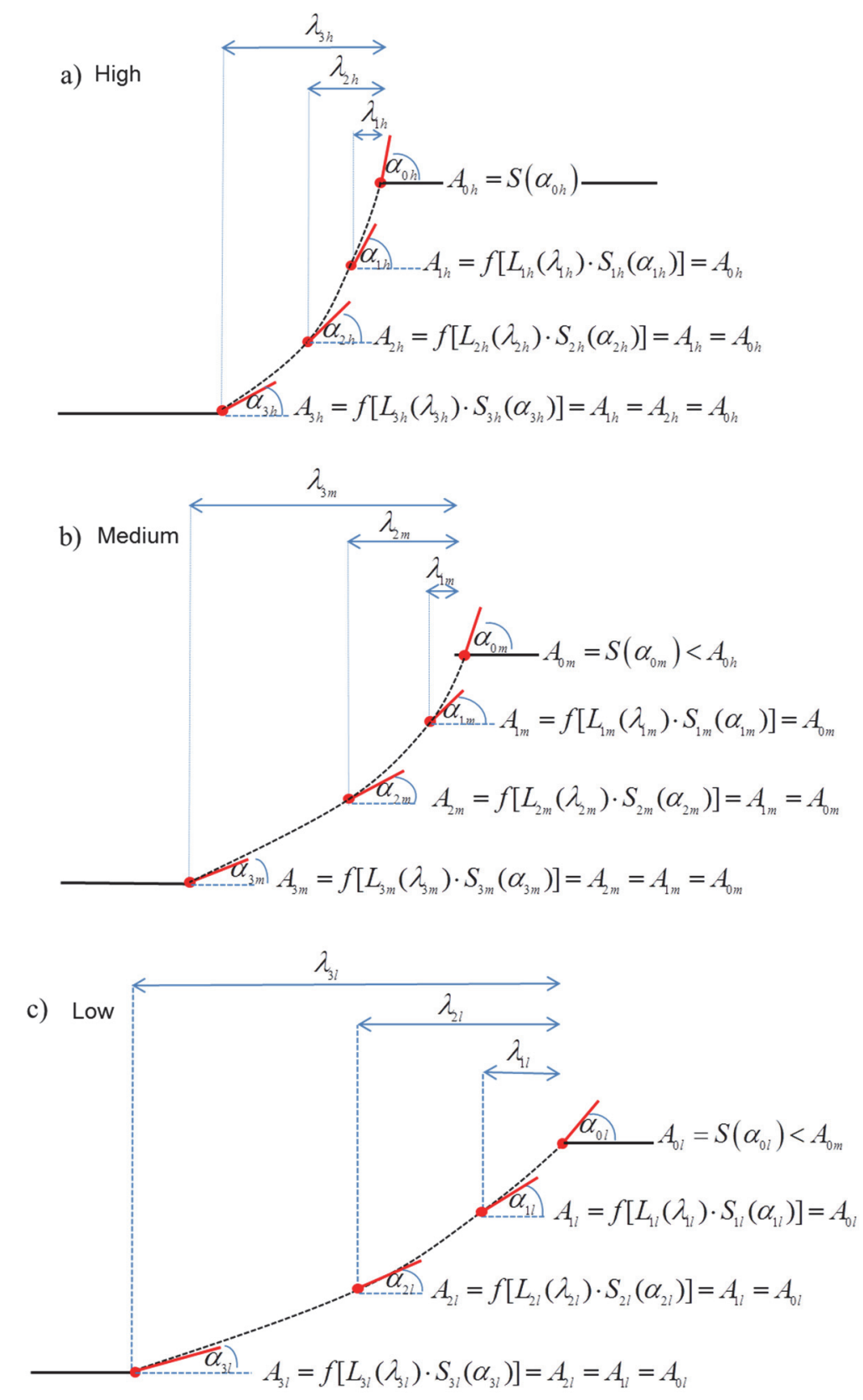

Figure 4. Potential family of concave slopes with constant rates of erosion: (a) high rate, (b) intermediate rate, and (c) low rate.

For slope lengths of 0.92 to $4.6 \mathrm{~m}(3$ to $15 \mathrm{ft})$, the RUSLE2 method employs a linear interpolation between the natural logarithm of equation 3 and the natural logarithm of equation 6 with $\lambda=4.6 \mathrm{~m}(15 \mathrm{ft})$ to calculate intermediate values of $L S$ (USDA-ARS, 2008). Notice that equation 3 is not a function of the slope length $\lambda$, and the same erosion rate is computed at any point on the profile that is shorter

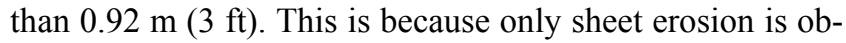
served for such short flow lengths (Meyer and Harmon, 1989).

As seen in the relationships above, $L S$ values are essentially time-invariant, with the value of $m$ depending primarily on soil type and slope steepness and the other $L S$ variables being constant. The other RUSLE2 factors $(R, K, C$, and $P)$, representing rainfall erosivity, soil erodibility, and management impacts, may vary greatly with time based on cli- mate and management changes. Although the actual erosion rate $A$ will change with these other factors, $L S$ and therefore the normalized erosion rate $A^{n}$ will remain constant. Once a stable equilibrium profile is achieved, the rate of slope recession may vary greatly with time as $R, K, C, P$, and $A$ change, but the slope shape will remain the same as controlled by the constant $A^{n}$.

\section{Discretization of Concave Slope Profile with LINEAR SEGMENTS OF EQUAL EROSION RATES}

By assuming that an equilibrium concave profile can be obtained from the assembly of a discrete number of small linear segments (fig. 5) in which the same normalized erosion rate holds on every segment, a selected initial normalized erosion rate $A_{1}{ }^{n}$ can be employed to determine the angle of the first linear segment $\alpha_{1}$ at the top of the slope. From 


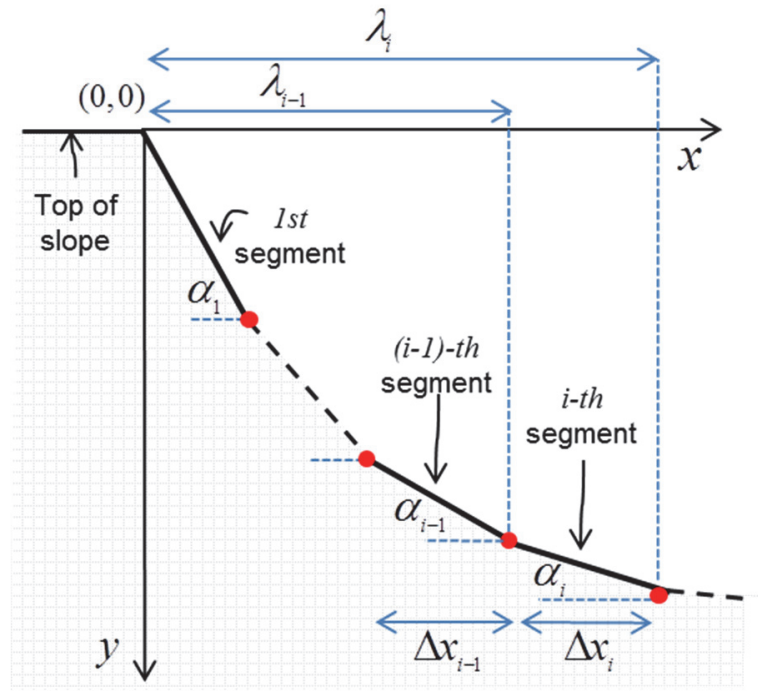

Figure 5. Discretization of slope profile into small linear segments.

this point forward, each subsequent segment must produce on average the same amount of normalized erosion $A_{1}{ }^{n}$ on the segment's length:

$$
A_{i}^{n}=\frac{p_{i}}{\Delta x_{i}}=A_{1}^{n}
$$

where $A_{i}{ }^{n}$ and $p_{i}$ are the $i$ th segment's normalized erosion rate and erosion production, respectively, and $\Delta x_{i}$ is the $i$ th segment's horizontal length. Erosion production is defined as the total normalized erosion times the total horizontal distance at a particular point in the profile. Therefore, $p_{i}$ becomes the difference between the erosion produced at the initial and final points of the $i$ th segment (fig. 5). Making use of equation $2, p_{i}$ can be expressed as:

$$
p_{i}=L S\left(\lambda_{i}, \alpha_{i}\right) \cdot \lambda_{i}-L S\left(\lambda_{i-1}, \alpha_{i-1}\right) \cdot \lambda_{i-1}
$$

Subsequently, the normalized erosion rate on the $i$ th segment becomes:

$$
A_{i}^{n}=\frac{L S\left(\lambda_{i}, \alpha_{i}\right) \cdot \lambda_{i}-L S\left(\lambda_{i-1}, \alpha_{i-1}\right) \cdot \lambda_{i-1}}{\Delta x_{i}}=A_{1}^{n}
$$

Having a known initial normalized erosion rate $A_{1}{ }^{n}$ and making the length of the first slope segment $\Delta x_{1}=\lambda_{1}=$ $0.92 \mathrm{~m}$ (because erosion calculations are invariant below this point), $\alpha_{1}$ can be determined, and with it the coordinates of the end point of the first segment using simple trigonometry, with the initial point as the origin of the coordinate system (fig. 5). Equation 9 is then used to obtain the coordinates of the lower end of the second segment. Here, $\lambda_{2}=\lambda_{1}=\Delta x(\Delta x$ is the selected horizontal length of each subsequent linear segment) and $A_{2}{ }^{n}=A_{1}{ }^{n}$, so $\alpha_{2}$ is the only remaining variable. Notice that $\alpha_{i-1}$ is always known, so $\alpha_{i}$ is the only variable to be determined. Repeating this process, the angle of all the subsequent segments can be determined along with the associated $(x, y)$ coordinates of each point, with $\lambda$ corresponding to the $x$ coordinate. Notice also that, in the selected reference frame, the $x$-axis is positive to the right and the $y$-axis is pos- itive downward. Given the recursive nature of the proposed methodology and the non-linearity of the $L S$ equations, a numerical solution for $\alpha_{i}$ was implemented.

At the top of the slope $(\lambda \leq 0.92 \mathrm{~m})$, the erosion is dominated by raindrop detachment. Therefore, the prediction of the slope contour results in a linear segment. However, here the overland flow path length is not important, and the linear shape of the first segment can be arbitrarily modified such that it preserves the overall slope shape predicted for $\lambda>$ $0.92 \mathrm{~m}(3 \mathrm{ft})$. A third-order polynomial of the following form:

$$
V(\lambda)=a_{1} \cdot \lambda^{3}+a_{2} \cdot \lambda^{2}+a_{3} \cdot \lambda+a_{4}
$$

was chosen to construct a cubic spline for $\lambda \in[0,0.92 \mathrm{~m}]$. The boundary conditions are:

$$
V(\lambda)=0, \text { at } \lambda=0
$$

$$
\begin{gathered}
V(\lambda)=0.92 \cdot \tan \alpha_{1}, \text { at } \lambda=\Delta x_{1}=0.92 \mathrm{~m}(3 \mathrm{ft}) \\
\frac{d V(\lambda)}{d \lambda}=\tan \alpha_{2}, \text { at } \lambda=\Delta x_{1}=0.92 \mathrm{~m}(3 \mathrm{ft})
\end{gathered}
$$

To satisfy a continuity condition:

$$
\frac{d^{2} V(\lambda)}{d \lambda^{2}}=0, \text { at } \lambda=\Delta x_{1}=0.92 \mathrm{~m}(3 \mathrm{ft})
$$

After imposing these boundary conditions on equation 10 , the problem becomes a linear system of equations that will provide the resulting values of $\alpha_{1}, \alpha_{2}, \alpha_{3}$, and $\alpha_{4}$ defining the polynomial function. Different functions are obtained for different initial normalized erosion rates $A_{1}{ }^{n}$.

\section{Sustainable Slopes: Mechanical AND EROSION STABILITY}

The approach described above produces a family of concave profiles satisfying the water erosion equilibrium condition. However, a truly stable slope must be stable for both mechanical and water erosion processes. Employing the critical slope contour approximation proposed by Jeldes et al. (2015b), those steady concave shapes that also have longterm stability were investigated (for a given mechanical soil strength defined by the Mohr-Coulomb parameters of friction angle $\phi$, cohesion $c$, and unit weight $\gamma$ ), using the following relationship:

$$
x=\left\{\begin{array}{cc}
0 & -h_{c r} \leq y \leq 0 \\
M \cdot\left[\sigma_{y} \cdot(B-1) \cdot(\operatorname{cosec} \phi-1)\right. & \\
+H \cdot B \cdot(\operatorname{cosec} \phi+1)] & y>0
\end{array}\right.
$$

$$
\begin{aligned}
& \text { where } \quad M=\frac{\cos \phi}{2 \cdot \gamma \cdot(1-\sin \phi)} \\
& B=\ln \left[\frac{\sigma_{y}}{H} \cdot\left(\frac{1-\sin \phi}{1+\sin \phi}\right)+1\right]=\ln \left[\frac{\sigma_{y}}{H} \cdot K_{a}+1\right]
\end{aligned}
$$




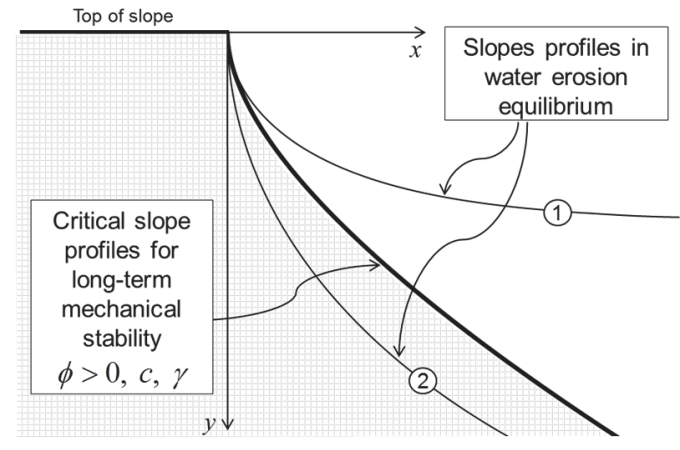

Figure 6. Steady-state or sustainable slope (profile 1) and a mechanically non-stable slope with cyclic morphology changes (profile 2).

$$
\begin{gathered}
\sigma_{y}=\gamma \cdot y \\
H=c \cdot \cot \phi \\
h_{c r}=\frac{2 \cdot c \cdot \cos \phi}{\gamma \cdot(1-\sin \phi)}
\end{gathered}
$$

In these relationships $H$ is the tensile strength of the soil, $K_{a}=(1-\sin \phi) /(1+\sin \phi)$ is the Rankine active coefficient of earth pressure, $\sigma y$ is the geo-static vertical stress, and $h_{c r}$ is the height of the tension zone. The equation describes a slope contour in the quadrant with the $x$-axis positive to the right and the $y$-axis positive downward, with $h_{c r}$ lying above the $x$-axis (Jeldes et al., 2015b). Because in practice $h_{c r}$ does not significantly affect the mechanical slope behavior, the top of the slope coincides with the $x$-axis for the analyses presented here. In most instances, the sharp cusp at the origin of the coordinate system (fig. 6) would not exist (i.e., a rounded intersection between the top and the face of the slope); however, there are cases where such sharp cusps exist in weakly or moderately cemented materials (Collins and Sitar, 2008, 2011). In this article, the sharp cusp is maintained to be consistent with the theoretical mathematical solution.

Slopes in erosion equilibrium that are less steep than the critical slope described by equations 15 through 20 are mechanically stable, while steeper slopes are unstable. This is illustrated in figure 6, where two different slopes in erosion equilibrium are shown for a soil defined by unique $\phi, c$, and $\gamma$. Here, profile 1 satisfies both the erosion and mechanical equilibrium requirements, and therefore becomes a sustainable slope with a steady-state shape over time. Profile 2, on the other hand, only satisfies erosion equilibrium, and mechanical failures are expected, which would alter the erosion equilibrium shape. However, natural adjustments may bring the slope to a new erosion equilibrium state that, if not mechanically stable, will repeat the failure and natural re-shaping process, creating cyclic changes in morphology over time.

\section{RESULTS AND DISCUSSION}

\section{Concave Slopes With Constant ERosion RATE}

A family of concave slopes with constant rates of normalized erosion $\left(A_{1}{ }^{n}=0.506\right.$ to 1.068$)$ along the profile is shown in figure 7 . This range of constant normalized erosion rates

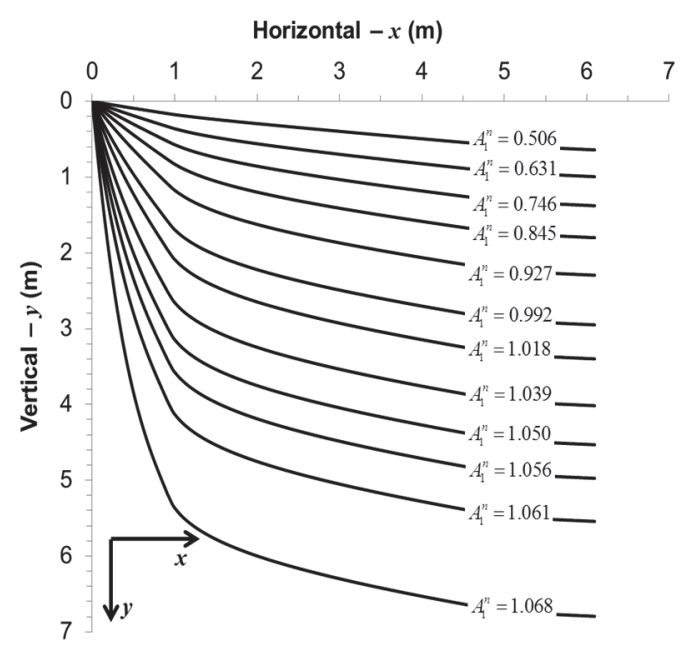

Figure 7. Family of concave slopes with constant rate of normalized erosion (equilibrium erosion profiles).

allows for top segments (steepest slope section) with inclinations ranging from $10^{\circ}$ to $80^{\circ}$. These concave slopes are the result of a numerical solution of equations 9 through 14, with a discretization length of $\Delta x=0.03 \mathrm{~m}(0.1 \mathrm{ft})$. This length was selected to be small enough such that the ratio $\alpha_{i} / \alpha_{i-1}$ remained within the range of 0.9 to 0.99 for the majority of the slope length. The computations stopped when $\alpha_{i}$ fell below $3^{\circ}$. In this family of profiles, there is a clear increase in the overall slope steepness as $A_{1}{ }^{n}$ increases. The overall steepness, defined as the slope of a straight line that connects the origin (top of slope) with the base (toe of slope), increases at a much faster rate for $A_{1}{ }^{n} \geq 1$ (fig. 8). This means that the predicted equilibrium concave profiles are more sensitive to values of $L S \geq 1$. Although the entire family of profiles is in erosion equilibrium (equal normalized erosion rate along the profile), these concave slopes may or may not be mechanically stable, so their stability must be analyzed based on the critical concave slope concept.

Notice that, in the analyses, constant normalized erosion is implied for the whole extent of the concave slope. In reality, when the concave slope encounters a relatively horizontal surface (e.g., at the bottom of the slope), part of the detached soil is deposited. For erosion to occur along a slope, the transport capacity of the flow $\left(T_{c}\right)$ must be greater than

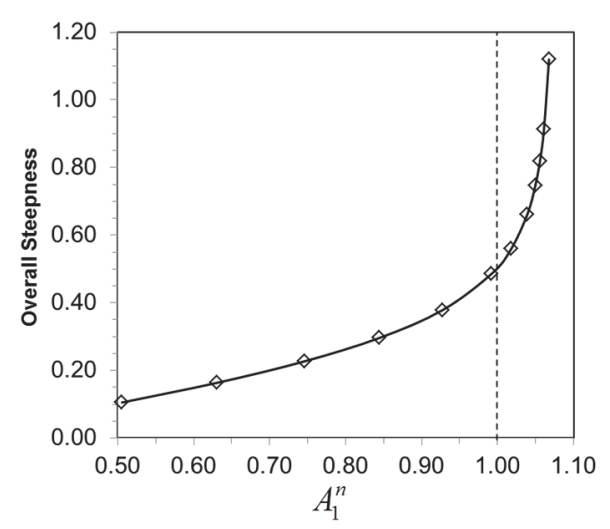

Figure 8. Overall steepness (defined as the slope of a straight line that connects the top and bottom of the profile) increases at a much faster rate for $A_{1}{ }^{n} \geq 1$, denoted by the dashed line. 
its sediment load $(q)$. Transport capacity is a measure of how much sediment the runoff can carry and therefore is a function of the kinetic energy of the flow, which decreases as the slope becomes less steep. When the flow reaches a relatively flat area, $T_{c}$ becomes less than $q$, and the flow is not capable of detaching new soil nor transporting the eroded soil, leading to deposition. Even though the employed equations do not capture this deposition effect (i.e., the concave slope shape is mathematically developed from top to bottom based on normalized erosion), the eroding portion of the profile will not be affected by deposition. Because the portion of the slope that can be affected by deposition is only a fraction of the profile, we assume for simplicity that the eroded materials are carried outside the slope, and the profile, with a constant normalized erosion rate, remains as predicted.

\section{SuSTAINABLE SLOPES}

Figure 9 illustrates the sustainable slope concept for a medium soft clay soil with $\phi=20^{\circ}$ and $c / \gamma=1 \mathrm{~m}$ (e.g., a soil with $c=20 \mathrm{kPa}$ and $\gamma=20 \mathrm{kN} \mathrm{m}^{-3}$ ). Using equations 15 through 20, the critical concave slope (with a factor of safety $F S=1$ ) for this specific soil was determined and plotted together with the normalized erosion equilibrium shapes. For the purpose of this comparison, the vertical tension zone of height $\left|h_{c r}\right|$ is not displayed. The results suggest that for this specific soil, normalized erosion equilibrium slopes with $A_{1}{ }^{n}$ $\leq 1.05$ would be mechanically stable and therefore would be sustainable with steady shapes over time. On the other hand, equilibrium concave shapes with $A_{1}{ }^{n}>1.05$ (shown with dashed lines in fig. 9) are likely to experience mechanical failures, so changes in morphology and high delivery rates would be likely. A second case is illustrated in figure 10 for a sandy soil with $\phi=30^{\circ}$ and $c / \gamma=0.5 \mathrm{~m}$. In this case, normalized erosion equilibrium shapes with $A_{1}{ }^{n} \leq 1.039$ will be sustainable, while concave shapes with $A_{1}{ }^{n}>1.039$ will not. Note that $A_{1}{ }^{n}=1.05$ and 1.039 are approximated limiting values $\left(A_{L}^{n}\right)$ that separate sustainable and non-sustainable concave slopes for the given soil mechanical properties. Similar chart results can be constructed for a wide range of

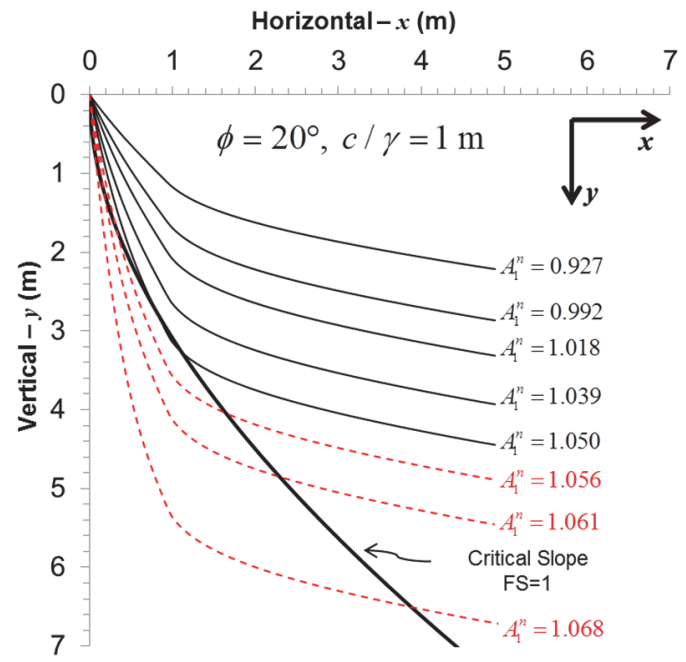

Figure 9. Normalized erosion equilibrium profiles and critical concave contour for $\phi=20^{\circ}$ and $c / \gamma=1 \mathrm{~m}$. Concave slopes with $A_{1}{ }^{n} \leq 1.05$ are considered sustainable.

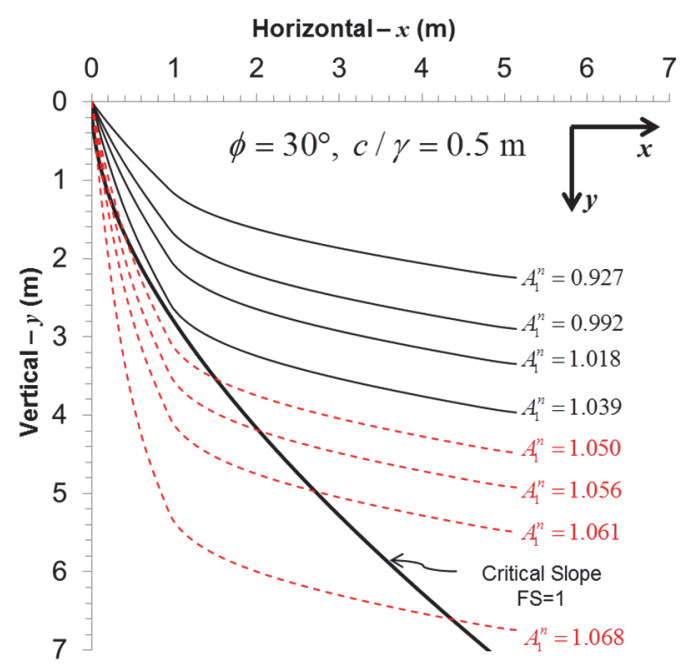

Figure 10. Normalized erosion equilibrium profiles and critical concave contour for $\phi=30^{\circ}$ and $c / \gamma=0.5 \mathrm{~m}$. Concave slopes with $A_{1}{ }^{n} \leq 1.039$ are considered sustainable.

mechanical soil properties (e.g., $\phi=20^{\circ}$ to $40^{\circ} ; c / \gamma=0.5$ to $3 \mathrm{~m})$. Generalized values of $A_{L}{ }^{n}$ are shown in figure 11 as a function of $\phi$ and $c / \gamma$. From this chart, the following approximation for $A_{L}{ }^{n}$ is proposed. For the ranges of $A_{1}{ }^{n}, \phi$, and $c / \gamma$ investigated here, concave normalized erosion equilibrium slopes will be sustainable if:

$$
A_{1}^{n} \leq 0.02 \cdot \frac{\gamma}{c} \cdot \ln (\tan \phi)+0.01 \cdot \frac{c}{\gamma}+1.06
$$

In practice, slopes are rarely designed for mechanical stability with $F S=1$, as some additional margin of safety is desired. Depending on the conditions and the impact of potential failure, slopes are designed for a selected minimum $F S$ that is always greater than 1 . The concept of sustainable slopes can be extended by introducing critical concave contours with $F S>1$ (Jeldes et al., 2015a). For example, figure 12 shows normalized erosion equilibrium slopes and concave shapes satisfying $F S=1.5$ for $\phi=20^{\circ}, 25^{\circ}, 30^{\circ}, 35^{\circ}$ and $40^{\circ}$ and $c / \gamma=0.5,1,1.5$, and $2 \mathrm{~m}$. Normalized erosion equilibrium slopes less steep than the critical contour for a given set of $\phi$ and $c / \gamma$ values will be sustainable, and their

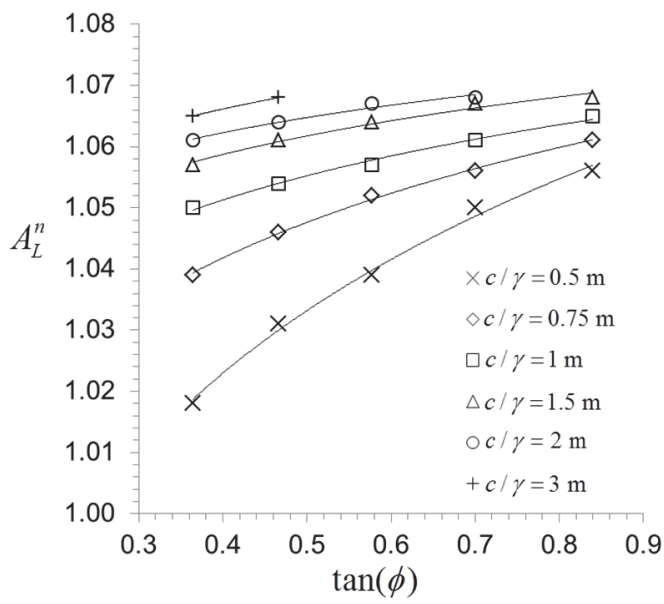

Figure 11. Limiting values of normalized erosion $\left(A_{L}\right)$ defining sustainability. 


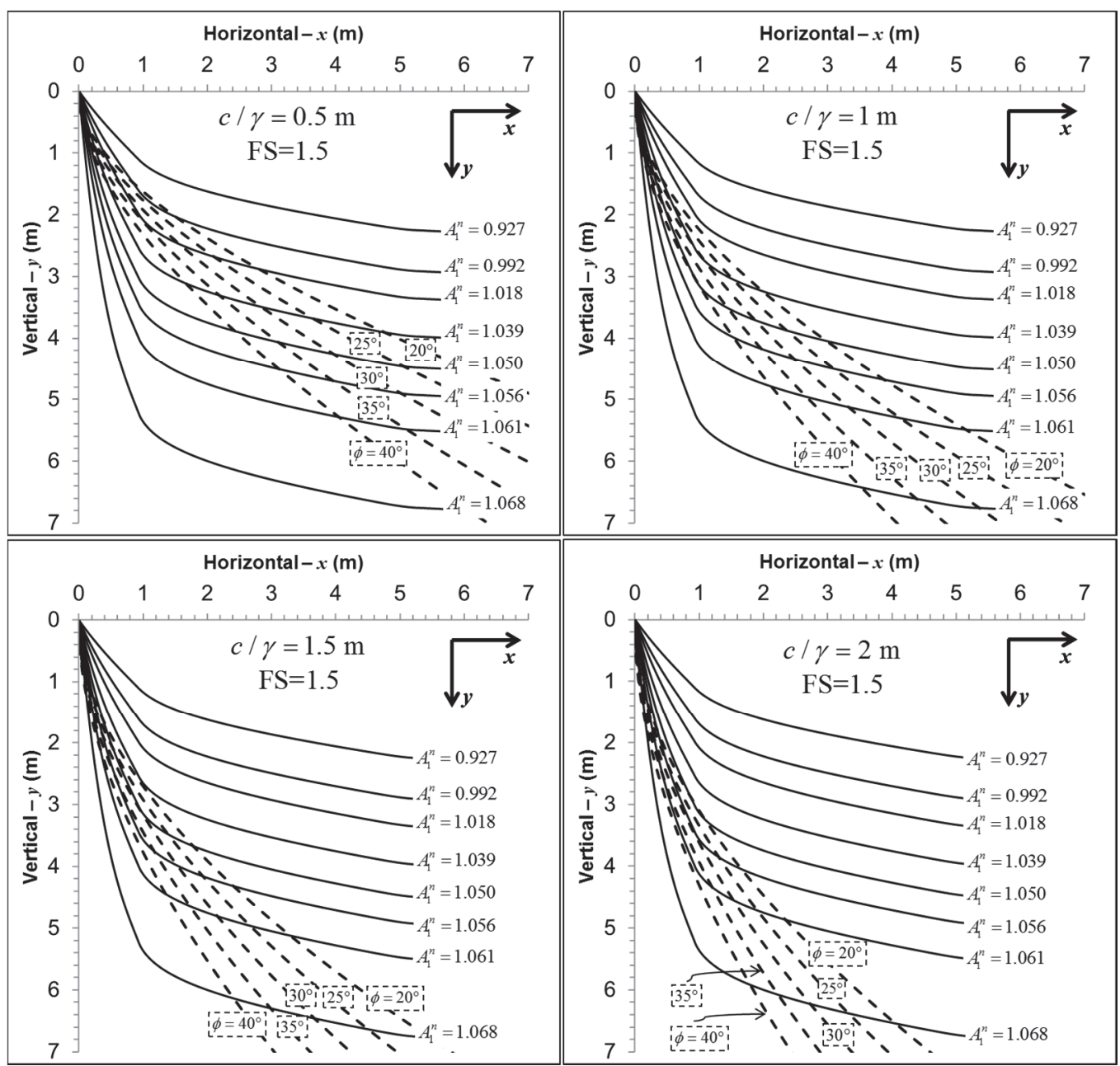

Figure 12. Normalized erosion equilibrium profiles and concave contours with $F S=1.5$.

shear strength along the most critical failure surface will be at least $50 \%$ greater than that required to maintain mechanical equilibrium in the long-term. Similar charts can be constructed for other desired $F S$ values.

This article has presented the argument that slopes in nature are seldom planar, and concave profiles are naturally formed as a result of evolutionary processes that seek erosion equilibrium. The logical conclusion is that constructed profiles should not be planar but rather should be of a more sustainable natural shape. The results presented here suggest that concave slopes can be constructed to achieve both minimal steady-state erosion equilibrium and mechanical stability. The desired profile could be selected by balancing allowable erosion rates and desired mechanical stability for specific site conditions and regulation requirements, such as discharge into sensitive waterbodies, highly erodible soils, and space limitations. Figure 12 can then be used as a design tool for the construction of slopes reflecting more natural landforms, while minimizing sediment delivery during initial slope shape adjustments. For cases where the location of the engineered slope toe and/or crest is dictated by constraints of space availability, the proposed methodology could be used as a starting point upon which further iterations or modifications could be applied to find the shape that best suits the needs of the specific project. If this is done, erosion and sediment control activities to handle the eroded sediment can be less rigorous and more effective. The increasing precision of GPS-based construction equipment suggests that such complex landforms can be now achieved with high accuracy, while deviations in the constructed slope profile due to typical construction inaccuracies do not compromise the stability of concave slopes (Jeldes et al., 2015a). With current construction technology, sustainable concave slopes can become more than a theoretical exercise.

\section{LIMITATIONS OF THIS WORK}

The methodology presented here has limitations that must be acknowledged. First, the topographic equations of RUSLE2 provide the fundamental prediction of normalized erosion equilibrium slopes. However, RUSLE2 is validated for slope angles less than or equal to $45^{\circ}$, while this analysis used initial normalized erosion rates that sometimes required an initial angle (angle of the first segment $\Delta x_{1}=\lambda_{1}=0.92 \mathrm{~m}$ ) that exceeded this definition. For example, the normalized erosion equilibrium slope defined for $A_{1}{ }^{n}=0.927$ requires an initial angle of $50^{\circ}$, while the slope defined for $A_{1}{ }^{n}=1.068$ requires an initial angle of $80^{\circ}$. In this sense, the limits of the empirical basis on which RUSLE2 was developed have been stretched. However, as the flow path crosses the $\lambda=0.92 \mathrm{~m}$ limit, the angles rapidly decrease and fall below the $45^{\circ}$ def- 


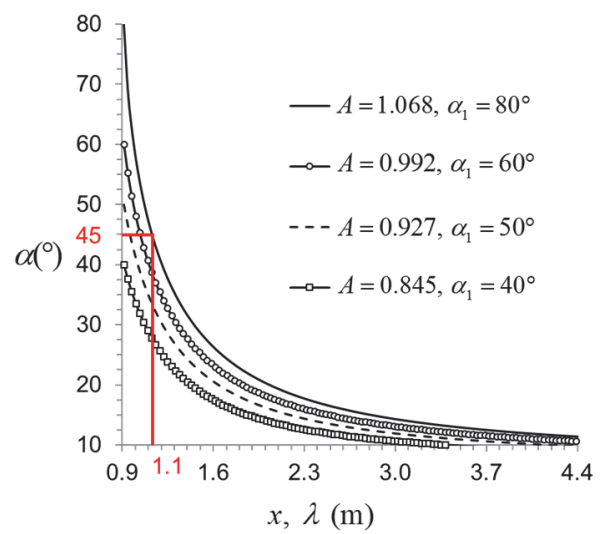

Figure 13. Computed slope angles versus horizontal slope length.

inition (fig. 13). Notice that the angles of the concave slope with the highest normalized erosion rate $\left(A_{1}{ }^{n}=1.068\right)$ reach $45^{\circ}$ at $x=1.3 \mathrm{~m}$; therefore, the assumption that RUSLE2 holds for $\alpha>45^{\circ}$ only affects a small portion of the slope. Future observational work on slopes steeper than $45^{\circ}$ with short flow paths would be required to validate the solution for such steep initial segments. What if extrapolation beyond the normal RUSLE2 limit causes the top segment's normalized erosion rate to be somewhat different from expected? That would not invalidate the approach; it would simply shift the result to another of the normalized erosion curves.

In addition, natural slopes often include a convex portion at the top, which may be the result of runoff coming over the top edge of the slope, increasing the soil detachment on a section that otherwise is only affected by sheet erosion. This effect was not included in this model, and future work is needed to understand and model this complex mechanism. Finally, this approach does not consider the effects of transient subsurface flow, nor the short-term stability of sustainable slopes. However, once the desired sustainable concave shape has been selected, the effects of transient groundwater flow can be investigated using commercial slope stability software. Similarly, the short-term stability could be evaluated once the site-specific undrained shear strength has been determined.

\section{CONCLUSIONS}

Natural landforms adjust their shape over time in order to seek erosion and sediment transport equilibrium. The resulting equilibrium shape is usually concave with a uniform erosion rate along the profile. In theory, this equilibrium shape would not suffer further adjustments, so the total erosion production is minimized. In this article, a conceptual model was offered in an attempt to explain how concave equilibrium shapes slopes are formed in nature. It was also shown that the equilibrium shape is not unique, and a family of potential slope profiles can exist according to the level of assumed constant normalized erosion experienced by the slope.

The fundamental RUSLE2 model with the assumption of a steady-state slope shape as represented by a time-invariant $L S$ value was used to develop a set of equations describing concave slopes in normalized erosion equilibrium at differ- ent levels of constant normalized erosion potential. This does not assume that the actual erosion rate is time-invariant, as that will depend on time-varying rainfall erosivity and management. It rather means that the slope may recede at different rates in time, but it will maintain the same overall slope shape during that recession. The resulting concave profiles were compared with critical (mechanical stability) concave slopes $(F S=1)$ and concave slopes having $F S=1.5$, illustrating how slope shapes can satisfy both normalized erosion equilibrium and the desired degree of mechanical stability. A mathematical expression defining the limiting normalized erosion at which normalized equilibrium erosion shapes become sustainable was provided as a function of the Mohr-Coulomb parameters, and the limitations of this work were discussed. The obtained results suggest that concave slopes can be constructed to achieve both minimal steadystate normalized erosion equilibrium as well as mechanical stability, and that the slope profile can be chosen such that erosion rates and desired mechanical stability are balanced to satisfy site conditions and regulatory requirements. Sustainable concave slopes can contribute to the growing need for environmentally friendly techniques for landform construction and sustainable land management, becoming an attractive alternative to the traditional planar slopes that are typically constructed today.

\section{REFERENCES}

Abrahams, A. D. (1968). Distinguishing between the concepts of steady-state and dynamic equilibrium in geomorphology. Earth Sci. J., 2(2), 160-166.

Ahnert, F. (1994). Equilibrium, scale, and inheritance in geomorphology. Geomorphology, 11(2), 125-140. https://doi.org/10.1016/0169-555x(94)90077-9

Bracken, L. J., \& Wainwright, J. (2008). Equilibrium in the balance? Implications for landscape evolution from dryland environments. Geol. Soc., 296(1), 29-46. https://doi.org/10.1144/SP296.3

Collins, B. D., \& Sitar, N. (2008). Processes of coastal bluff erosion in weakly lithified sands, Pacifica, California, USA. Geomorphology, 97(3), 483-501. https://doi.org/10.1016/j.geomorph.2007.09.004

Collins, B. D., \& Sitar, N. (2011). Stability of steep slopes in cemented sands. J. Geotech. Geoenviron. Eng., 137(1), 43-51. https://doi.org/10.1061/(ASCE)GT.1943-5606.0000396

Foster, G. R., Meyer, L. D., \& Onstad, C. S. (1977). A runoff erosivity factor and variable slope length exponents for soil loss estimates. Trans. ASAE, 20(4), 683-687. https://doi.org/10.13031/2013.35628

Goldrick, G., \& Bishop, P. (2007). Regional analysis of bedrock stream long profiles: Evaluation of Hack's SL form, and formulation and assessment of an alternative (the DS form). Earth Surf. Proc. Landforms, 32(5), 649-671. https://doi.org/10.1002/esp.1413

Gray, D. H. (2013). Influence of slope morphology on the stability of earthen slopes. Proc. Geo-Congress (pp. 1895-1904). Reston, VA: ASCE. https://doi.org/10.1061/9780784412787.191

Hack, J. T. (1960). Interpretation of erosional topography in humid temperate regions. American J. Sci., 258, 80-97.

Jeldes, I. A., Drumm, E. C., \& Yoder, D. C. (2015a). Design of stable concave slopes for reduced sediment delivery. J. Geotech. Geoenviron. Eng., 141(2), 04014093. https://doi.org/10.1061/(ASCE)GT.1943-5606.0001211 
Jeldes, I. A., Vence, N. E., \& Drumm, E. C. (2015b). Approximate solution to the Sokolovskii concave slope at limiting equilibrium. Intl. J. Geomech., 15(2), 04014049. https://doi.org/10.1061/(ASCE)GM.1943-5622.0000330

Larue, J.-P. (2008). Effects of tectonics and lithology on long profiles of 16 rivers of the southern Central Massif border between the Aude and the Orb (France). Geomorphology, 93(34), 343-367. https://doi.org/10.1016/j.geomorph.2007.03.003

Leopold, L. B., \& Langbein, W. B. (1962). The concept of entropy in landscape evolution. Reston, VA: U.S. Geological Survey.

McCool, D., Foster, G., Mutchler, C., \& Meyer, L. (1989). Revised slope length factor for the Universal Soil Loss Equation. Trans. ASAE, 32(5), 1571-1576. https://doi.org/10.13031/2013.31192

Meyer, L. D., \& Harmon, W. C. (1989). How row-sideslope length and steepness affect interrill erosion. Trans. ASAE, 32(2), 639644. https://doi.org/10.13031/2013.31050

Miyamoto, H., Baker, V., \& Lorenz, R. (2005). Entropy and the shaping of the landscape by water. In A. Kleidon \& R. Lorenz (Eds.), Non-equilibrium thermodynamics and the production of entropy: Life, earth, and beyond (Vol. 2, pp. 135-146). Berlin, Germany: Springer. https://doi.org/10.1007/11672906_11

Molnár, P., \& Ramírez, J. A. (1998). Energy dissipation theories and optimal channel characteristics of river networks. Water Resour. Res., 34(7), 1809-1818. https://doi.org/10.1029/98WR00983

Montgomery, D. R. (2001). Slope distributions, threshold hillslopes, and steady-state topography. American J. Sci., 301(4-5), 432454. https://doi.org/10.2475/ajs.301.4-5.432

Nash, D. (1980). Forms of bluffs degraded for different lengths of time in Emmet county, Michigan, USA. Earth Surf. Proc. Landforms, 5(4), 331-345. https://doi.org/10.1002/esp.3760050405

Pelletier, J. D., \& Rasmussen, C. (2009). Quantifying the climatic and tectonic controls on hillslope steepness and erosion rate. Lithosphere, 1(2), 73-80. https://doi.org/10.1130/L3.1

Penck, W. (1953). Morphological analysis of land forms: A contribution to physical geology. New York, NY: St. Martin's Press.

Phillips, J. D. (2011). Emergence and pseudo-equilibrium in geomorphology. Geomorphology, 132(3-4), 319-326. https://doi.org/10.1016/j.geomorph.2011.05.017

Rieke-Zapp, D. H., \& Nearing, M. A. (2005). Slope shape effects on erosion: A laboratory study. SSSA J., 69(5), 1463-1471. https://doi.org/10.2136/sssaj2005.0015

Rodríguez-Iturbe, I., Rinaldo, A., Rigon, R., Bras, R. L., Marani, A., \& Ijjasz-Vasquez, E. (1992). Energy dissipation, runoff production, and the three-dimensional structure of river basins. Water Resour. Res., 28(4), 1095-1103. https://doi.org/10.1029/91WR03034

Schor, H. J., \& Gray, D. H. (2007). Landforming: An environmental approach to hillside development, mine reclamation and watershed restoration. Hoboken, NJ: John Wiley \& Sons. https://doi.org/10.1002/9780470259900

Schumm, S. A. (1956). The role of creep and rainwash on the retreat of badland slopes. American J. Sci., 254(11), 693-706. https://doi.org/10.2475/ajs.254.11.693

Smith, T. R., Merchant, G. E., \& Birnir, B. (2000). Transient attractors: Towards a theory of the graded stream for alluvial and bedrock channels. Comput. Geosci., 26(5), 541-580. https://doi.org/10.1016/S0098-3004(99)00128-4

Snyder, N. P., Whipple, K. X., Tucker, G. E., \& Merritts, D. J. (2000). Landscape response to tectonic forcing: Digital elevation model analysis of stream profiles in the Mendocino triple junction region, northern California. Bull. Geol. Soc. America, 112(8), 1250-1263. https://doi.org/10.1130/00167606(2000)112<1250:LRTTFD $>2.3 . C O ; 2$

Sokolovskii, V. V. (1960). Statics of soil media. London, UK: Butterworths Scientific.

Thorn, C. E., \& Welford, M. R. (1994). The equilibrium concept in geomorphology. Ann. Assoc. American Geographers, 84(4), 666-696. https://doi.org/10.1111/j.1467-8306.1994.tb01882.x

Twidale, C. R. (2007). Backwearing of slopes: The development of an idea. Revista Cuaternario y Geomorfologia, 21(1-2), 135146.

Twidale, C. R., \& Milnes, A. R. (1983). Slope processes active late in arid scarp retreat. Zeitshcrift für Geomorphologie, 27(3), 343361.

USDA-ARS. (2008). Science documentation: Revised Universal Soil Loss Equation Version 2 (RUSLE2). Washington, DC: USDA Agricultural Research Service. Retrieved from http://www.ars.usda.gov/sp2UserFiles/Place/64080510/RUSLE/ RUSLE2_Science_Doc.pdf

Utili, S., \& Nova, R. (2007). On the optimal profile of a slope. Soils Foundations, 47(4), 717-729. https://doi.org/10.3208/sandf.47.717

Vahedifard, F., Shahrokhabadi, S., \& Leshchinsky, D. (2016a). Geosynthetic-reinforced soil structures with concave facing profile. Geotext. Geomembr., 44(3), 358-365. https://doi.org/10.1016/j.geotexmem.2016.01.004

Vahedifard, F., Shahrokhabadi, S., \& Leshchinsky, D. (2016b). Optimal profile for concave slopes under static and seismic conditions. Canadian Geotech. J., 53(9), 1522-1532. https://doi.org/10.1139/cgj-2016-0057

Yang, C. T., \& Song, C. C. (1979). Theory of minimum rate of energy dissipation. J. Hydraul. Div., 105(7), 769-784.

Young, R. A., \& Mutchler, C. K. (1969). Soil movement on irregular slopes. Water Resour. Res., 5(5), 1084-1089. https://doi.org/10.1029/WR005i005p01084

Zhang, T., Cai, Q., Han, L., Shu, J., \& Zhou, W. (2017). 3D stability analysis method of concave slope based on the Bishop method. Intl. J. Mining Sci. Tech., 27(2), 365-370. https://doi.org/10.1016/j.ijmst.2017.01.020 